\title{
Prevalence of mistreatment among physiotherapy interns in Nigeria: a preliminary study
}

\author{
Daha Garba Muhammad ${ }^{1 *}$ (D, Yusuff Tunde Gbonjubola1', Ibrahim Ahmad Abubakar', Adekolurejo Tobi Elisha² and \\ Hassan Yusuf Ahmad ${ }^{3}$
}

\begin{abstract}
Background: Healthcare professionals with the least experience, such as students and interns, are likely to face some form of mistreatments in the world of health professionals. Mistreatment has a negative impact on the victim's well-being as it results in psychological distress such as burn out, lack of motivation and reduced performance. This study aims to explore mistreatment among physiotherapy interns in Nigeria with a view to protecting the future of the profession.

Result: Most of the participant were male (57.5\%) and doing their internship in the northwestern part of the country (42.5\%). Forty interns participated in the study, and $2 / 3$ of them had experience of mistreatment. The most common type of mistreatment was yelling or shouting (60\%), followed by someone taking credit for what an intern did (55\%), humiliation or belittlement (50\%), and threat of an extension beyond the 12 months (27.5\%). Eightyseven percent reported that the mistreatment changes their relationship with the perpetrator. Mistreatment led to stress in $70 \%$ of the respondent, affected the self-confidence of $62.5 \%$, and led to decreased clinical output in $45 \%$ of the participants. Forty percent of the participants acquired depression due to the mistreatment.

Conclusion: Most physiotherapy interns experience mistreatment during the 1-year mandatory clinical internship. Verbal abuse is the most prevalent form of mistreatment, while the least is physical abuse. This study found that mistreatment has adverse effects on the health and work output of physiotherapy interns.
\end{abstract}

Keyword: Stress, Verbal abuse, Suicide, Physiotherapy, Internship, Nigeria

\section{Background}

Mistreatment is an act that encompasses aggressive behaviours that show disrespect to the personality of an individual, which may be done intentionally or unintentionally $[1,2]$. Mistreatment in the health profession is not a new concept; however, it occurs in various forms [3]. Mistreatment may be verbal, physical, emotionally related or ethnic discrimination between the superiors and the subordinates and sometimes between coworkers [4-6]. Mistreatment in medical education is an

\footnotetext{
* Correspondence: dahagarba@gmail.com

${ }^{1}$ Physiotherapy Department, Abubakar Tafawa Balewa University Teaching Hospital, Bauchi, Nigeria

Full list of author information is available at the end of the article
}

international issue first documented by Henry Silver in the 1980s [7]. Healthcare professionals with the least experience, such as students and interns, are likely to face some form of mistreatment in the world of health professionals [8-10]. Mistreatment has a negative impact on the victim's well-being as it results in psychological distress such as burn out, lack of motivation and reduced performance $[11,12]$.

Upon induction into the physiotherapy profession, graduates take part in a 1-year internship in any accredited hospital under the supervision of experienced physiotherapists [13]. The period of physiotherapy internship is a very tasking one as they have to put up with the pressure of competitive and demanding professional

\section{Springer Open}

(0) The Author(s). 2021 Open Access This article is licensed under a Creative Commons Attribution 4.0 International License, which permits use, sharing, adaptation, distribution and reproduction in any medium or format, as long as you give appropriate credit to the original author(s) and the source, provide a link to the Creative Commons licence, and indicate if changes were made. The images or other third party material in this article are included in the article's Creative Commons licence, unless indicated otherwise in a credit line to the material. If material is not included in the article's Creative Commons licence and your intended use is not permitted by statutory regulation or exceeds the permitted use, you will need to obtain permission directly from the copyright holder. To view a copy of this licence, visit http://creativecommons.org/licenses/by/4.0/. 
training [14]. With very limited or no research on mistreatment among physiotherapy interns, Mukhtar reported the mistreatment of medical students during their training in Pakistan [14]. The issue of mistreatments among physiotherapy interns from the subSaharan African context seems to have drawn little or no attention, except for few related studies such as Owoaje Uchendu and Ige [15] that documented that almost all the respondents (98.5\%) had experienced one or more forms of mistreatment during their training. In summary, minimal research has investigated mistreatment in the physiotherapy profession. As such, the objective of this preliminary study was to explore mistreatment among physiotherapy interns in Nigeria with a view to protecting the future of the profession and healthcare at large.

\section{Methods}

\section{Study design}

Cross-sectional survey design was used in this study.

\section{Study population}

The population of this study comprises physiotherapy interns in Nigeria.

\section{Inclusion and exclusion criteria}

All interns of both genders in any age category undergoing internship training in any part of Nigeria were considered eligible. At the same time, the following were excluded: interns that do not consent and interns on extension (interns that have finished their 12 months training but were retained as a punishment for something wrong done or because there are no new interns to be taken).

\section{Sample size}

All population (Census) sample size was employed since the number of interns in Nigeria is few (less than 250).

\section{Sampling technique}

A purposive sampling technique was employed

\section{Study instrument}

An online questionnaire was utilized for this study since the study cut across every part of the country where physiotherapy interns are trained. Online questionnaires give comprehensive geographical coverage for data collection [16]. It also allows access to large samples at low cost with data collection neutrality, the possibility of anonymity and time to ponder on the matter [16]. This made this type of data collection internally reliable since the researchers cannot influence the participants [16]. The limitation includes high rate of unanswered questions, the impossibility of clarifying or debating the answers, superficial responses and selection bias [16]. It was reported that the use of non-conventional data collection methods involves creativity, planning and proficient use of the technique. As a result, the research is methodologically sound, which is paramount for producing consistent, reliable, and replicable data [17].

As English is the language of communication in Nigeria and due to the uncertainty on the participant's mother tongue's robustness, the questionnaires were filled in English. The questionnaire encloses closedended questions. The instrument of data collection was validated before being administered (content validity). It comprises three sections:

\section{Section A: Socio-demographic characteristics}

This includes age category, gender, hospital of internship training and institution of undergraduate training.

\section{Section B: Student's mistreatment questionnaire}

The questionnaire was adapted and modified from Owoaje et al. [15]. The questions inquire about the experience of mistreatment, the type of mistreatment and the effect of the mistreatment. Items included being shouted or yelled at; being belittled or humiliated; being assigned tasks for punishment rather than for educational value; having someone take credit for the respondent's work; being physically threatened; being hit, slapped, kicked, or pushed; and being threatened with an unfair grade; as well as experiencing sexual harassment, exploitation, or ethnic discrimination. The responses were noted with a yes or no option (Additional file 1).

\section{Section C: Reporting of mistreatment}

This part was adapted and modified from Iftikhar et al. [4]. It enquires about where the interns have ever reported mistreatment, and any action was taken. It further asked those that never reported the reasons for not reporting. The responses were noted with a yes or no option (Additional file 1).

\section{Data collection methods}

Ethical approval was sought and obtained from the Kano State Ministry of health research ethics committee with reference number 2104. The name of at least one intern from each training institution was collected. The purpose of the study was explained to them, and the link to the online questionnaire (Google form) was sent to each of the corresponding interns from each of the training centres. The corresponding intern was then requested to share the link to their WhatsApp group chat for other interns in the Centre to fill the questionnaire. To tackle some of the limitations, the corresponding intern was asked to clarify any questions by the interns since he/she is close to them. Because all the interns are inclusive and 
use WhatsApp, there was no risk of selection bias. A reminder was sent to the correspondence from each Centre at the end of each week.

\section{Data analysis procedure}

Descriptive statistic of frequency, percentages and pie chart were used to summarize the data. Chi-square was used to determine the association between categorical variables. All the analysis will be done using the Stata version 12 at an alpha level of $\alpha=0.05$.

\section{Results}

Forty interns completed and submitted the questionnaire, and all were considered for analysis. The study's response rate was poor (16\%) despite the questionnaire's wide distribution, as seen from the participants' demography. Participants from all six regions of Nigeria were recruited.

Table 1 shows the socio-demographic variables of the study participants. There was equal representation of participants in terms of age 20-25 and 26-30 (50\%) and almost equal gender distribution, with the male being slightly having a higher number (57.5\%) than female (42.5\%). Although the participants of the study cut across the three major tribes in Nigeria, Hausa dominated (45\%), followed by Yoruba (35\%) and Igbo (15\%). Most participants (57.5\%) at the time of the study had spent less than 4 months of their training while $25 \%$ had spent 5-8 months in the training. The study recruited participants from seven out of twelve (7/12) physiotherapy training institutions, with most participants (42.5\%) from Bayero University Kano. Also, the study recruited interns from every part of Nigeria, with a majority from the northwest (42.5\%) and the south-south (27.5\%).

Figure 1 shows that $2 / 3$ of the participant (67.5\%) were mistreated during the internship training.

Table 2 shows the type of mistreatment the participants were subjected to during their training. The most common type of mistreatment was yelling or shouting (60\%), followed by someone taking credit for what an intern did (55\%), humiliation or belittlement (50\%), the threat of an extension beyond the 12 months (87.5\%), disparaging remarks or negative comments (45\%), assignment or giving a task as a punishment $(27.5 \%)$, ethnic or religious discrimination (20\%), asked to do something immoral or unethical (20\%), sexual harassment $(12.5 \%)$ and threat to harm, slapping or hitting (7.5\%) respectively.

Table 3 shows the effects of mistreatment on the participants. Eighty-seven percent (87\%) reported that it changes their relationship with the perpetrator, while $70 \%$ reported that it causes them stress. It also affects the self-confidence of $62.5 \%$ and led to decreased clinical output in $45 \%$ of the participants. Forty percent of the
Table 1 The socio-demographic variables of the study participant

\begin{tabular}{|c|c|c|}
\hline Variables & $\mathrm{n}$ & $\%$ \\
\hline \multicolumn{3}{|l|}{$\overline{\text { Age }}$} \\
\hline $20-25$ & 20 & 50 \\
\hline $26-30$ & 20 & 50 \\
\hline \multicolumn{3}{|l|}{ Gender } \\
\hline Male & 23 & 57.5 \\
\hline Female & 17 & 42.5 \\
\hline \multicolumn{3}{|l|}{ Ethnicity } \\
\hline Hausa & 18 & 45 \\
\hline Igbo & 6 & 15 \\
\hline Yoruba & 14 & 35 \\
\hline Others & 2 & 5 \\
\hline \multicolumn{3}{|c|}{ Months of internship training } \\
\hline $1-4$ & 23 & 57.5 \\
\hline $5-8$ & 10 & 25 \\
\hline $9-12$ & 7 & 17.5 \\
\hline \multicolumn{3}{|c|}{ Institution of undergraduate training } \\
\hline 1 & 17 & 42.5 \\
\hline 2 & 1 & 2.5 \\
\hline 3 & 4 & 10 \\
\hline 4 & 6 & 15 \\
\hline 5 & 4 & 10 \\
\hline 6 & 6 & 15 \\
\hline 7 & 2 & 5 \\
\hline \multicolumn{3}{|c|}{ Region of internship training } \\
\hline North-west & 17 & 42.5 \\
\hline North-east & 2 & 5 \\
\hline North-central & 4 & 10 \\
\hline South-west & 5 & 12.5 \\
\hline South-east & 1 & 2.5 \\
\hline South-south & 11 & 27.5 \\
\hline
\end{tabular}

respondents acquired depression due to the mistreatment and $7.5 \%$ thought of committing suicide due to the mistreatment. Thirty-seven point five percent (37.5\%) regretted the choice of career while only a few resort to smoking and alcohol consumption (10\%).

Table 4 shows the participants who reported any mistreatment and reasons for not reporting. Only 15\% of the participants had ever reported mistreatment. Sixtyfive percent $(65 \%)$ of the participant attributed reporting becoming troublesome for them as one of reasons for not reporting. In comparison, $60 \%$ thought that reporting would not accomplish anything, 55\% thought that the problem would not be treated fairly or they would be labelled and $52.5 \%$ handled the problem themselves for fear of being blamed or that the reporting would not 


\section{mistreatment prevalence}

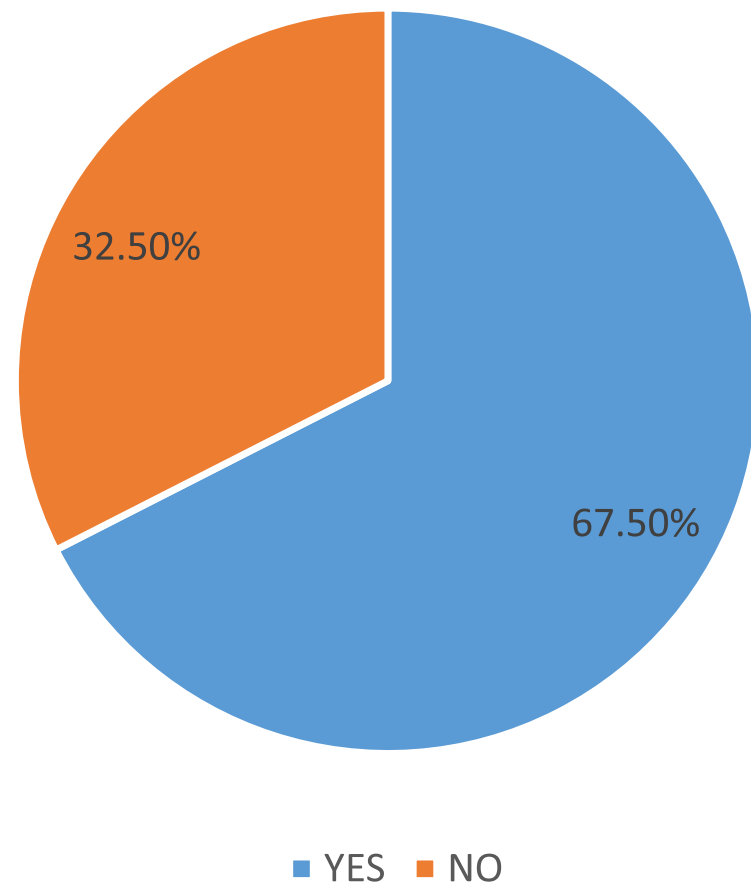

Fig. 1 prevalence of mistreatment among the participants

be kept confidential. Forty-two percent (42\%) use avoidance to cope with the mistreatment, and $15 \%$ did not know where to report the mistreatment.

Table 5 shows an association between sociodemographic variables and the prevalence of mistreatment. All the participants' socio-demographic variables were not significantly associated with the prevalence of mistreatment $(p>0.05)$.

Table 2 Type of mistreatment the participants

\begin{tabular}{lll}
\hline Type of mistreatment & Yes $\mathbf{n}(\%)$ & No $\mathbf{n}(\%)$ \\
\hline Yelled or shouted at & $24(60)$ & $16(40)$ \\
Humiliated or belittle & $20(50)$ & $20(50)$ \\
Disparaging remarks or negative comments & $18(45)$ & $22(55)$ \\
Assignment or task for punishment & $11(27.5)$ & $29(72.5)$ \\
Someone else took credit for student's work & $22(55)$ & $18(45)$ \\
Ethnic, religious or age discrimination & $8(20)$ & $32(80)$ \\
/harassment & & \\
Threat to extension & $19(47.5)$ & $21(52.5)$ \\
Sexual harassment or mistreatment & $5(12.5)$ & $35(87.5)$ \\
Threats to harm & $3(7.5)$ & $27(92.5)$ \\
Slapped, pushing, kicking or hitting & $3(7.5)$ & $27(92.5)$ \\
Asked to do something immoral or unethical & $8(20)$ & $32(80)$ \\
\hline
\end{tabular}

Table 3 The effects of the mistreatment on the participants

\begin{tabular}{lll}
\hline Variables & $\mathbf{n}$ & $\%$ \\
\hline Caused stress & 28 & 70 \\
Affected relationship with person & 35 & 87.5 \\
Affect self-confidence & 25 & 62.5 \\
Caused depression & 16 & 40 \\
Affected academic performance & 18 & 45 \\
Problem sleeping & 9 & 22.5 \\
Regret choice of career & 15 & 37.5 \\
Resort to alcohol & 4 & 10 \\
Resort to smoking & 4 & 10 \\
Consider suicide & 3 & 7.5 \\
\hline
\end{tabular}

\section{Discussion}

This study investigated mistreatment and its impacts among physiotherapy interns. It is the first report of physiotherapy interns' experiences of mistreatment during the mandatory clinical internship in Nigeria.

The prevalence of mistreatment among physiotherapy interns in our study was slightly above average (67.5\%). These results are consistent with the findings of earlier studies. For instances, $66 \%$ of medical students had experienced some form of mistreatment during their training in Pakistan [14]. However, the prevalence is lower

Table 4 The participants who reported any mistreatment and reasons for not reporting

\begin{tabular}{lll}
\hline Variables & $\mathbf{n}$ & $\%$ \\
\hline Ever Reported abuse & & \\
Yes & 6 & 15 \\
No & 34 & 85
\end{tabular}

\section{Reasons for not reporting}

I did not think that reporting abuse would accomplish $\quad 24 \quad 60^{a}$ anything

I considered that reporting abuse would become more $\quad 26 \quad 65^{a}$ troublesome than it was worth

I dealt with the problem directly myself $\quad 21 \quad 52.5^{\text {a }}$

I did not know to whom i should report abuse $\quad 6 \quad 15^{\text {a }}$

I was afraid that reporting abuse would adversely affect $\quad \begin{array}{lll}16 & 40^{\text {a }}\end{array}$ my evaluation

I was afraid that the reporting would not be kept $\quad 21 \quad 52.5^{2}$ confidential

I did not think that the problem would be dealt $\quad 22 \quad 55^{\text {a }}$ with fairly

I did not want to be labeled

I was concerned about being blamed

I did not want to think about the abusive experience $\quad \begin{array}{lll}17 & 42.5\end{array}$ further

I was afraid that the reporting would negatively influence my professional career in the future

${ }^{\mathrm{a}}$ This is a multiple response questions 
Table 5 Association between socio-demographic variables and the prevalence of mistreatment

\begin{tabular}{|c|c|c|c|c|}
\hline Variables & & & Chi-square & $p$-value \\
\hline & Yes & No & & \\
\hline Age & & & 0.11 & 0.73 \\
\hline $20-25$ & 14 & 6 & & \\
\hline $26-30$ & 13 & 7 & & \\
\hline Gender & & & 2.97 & 0.09 \\
\hline Male & 14 & 3 & & \\
\hline Female & 13 & 10 & & \\
\hline Months of internship training & & & 1.37 & 0.50 \\
\hline $1-4$ & 15 & 8 & & \\
\hline $5-8$ & 6 & 4 & & \\
\hline $9-12$ & 6 & 1 & & \\
\hline Institution of undergraduate training & & & 9.67 & $0-14$ \\
\hline BUK & 9 & 8 & & \\
\hline UNIMAID & 5 & 1 & & \\
\hline UI & 4 & 0 & & \\
\hline UNILAG & 3 & 1 & & \\
\hline OAU & 5 & 1 & & \\
\hline NAW & 1 & 0 & & \\
\hline Foreign train & 0 & 2 & & \\
\hline Region of internship training & & & 6.07 & 0.30 \\
\hline North-west & 9 & 8 & & \\
\hline North-east & 1 & 1 & & \\
\hline North-central & 2 & 2 & & \\
\hline South-west & 4 & 1 & & \\
\hline South-east & 1 & 0 & & \\
\hline South-south & 10 & 1 & & \\
\hline
\end{tabular}

than the rates reported from studies conducted by Mbada et al. [18] among physiotherapy students in Nigeria. This increase in mistreatment experienced by the interns might be due to the feeling of increased status among the participants as against when they were students. As such, they feel they deserve to be treated better than when they were students. Also, the variation may be due to differences in terms of methodology and the definitions of abuse. While Mbada et al. [18] used the term "bullying", "mistreatment" was used in this study. Abuse or perceived mistreatment are relatively broader terms that also encompass sexual harassment, whereas bullying includes threats to professional status and personal standing, isolation, overwork and destabilization [19].

The commonest form of mistreatment experienced by the interns was verbal abuse that included being yelled at (60\%), humiliated or belittled (50\%) and being targets of negative comments (45\%), which is in tandem with the report from Pakistan of which verbal abuse was reported to be the commonest form of mistreatment [20]. A higher rate (90\%) was reported in the study conducted among medical students in a Saudi medical school [20]. A very low (7.5\%) threat to harm was reported by our participants with a similar but slightly higher rate (18.8\%) reported in a similar but different study by Iftikhar et al. [4]. This disparity may be as a result of differences in the sample size as well as the sample studied.

Mistreatment has been shown to have negative effects on health providers' health and workplace output [12]. Participants of this study reported strained relationships with the perpetrators, reduced self-confidence, decreased clinical output, depression and regretted career choice, while only a few resort to smoking and alcohol. These factors have been shown to contribute to the psychological stress experienced by these individuals, who are already strained mentally and physically by the taxing nature of the one mandatory clinical internship $[14,21,22]$. 
Suicidal ideation is having the thought of intentionally causing one's own death [23, 24]. Only $3(7.5 \%)$ of the participant had the thought of suicide due to the mistreatment they face during internship training. This is similar to the findings that stated that suicidal thought among medical students ranges from 1.8 to $53.6 \%$. However, this is lower than the reported prevalence in South African [25] and Ethiopian [26] medical students. This could be due to the differences in the outcome measure used, geographical location, the setting where the participants were medical students instead of this study where the participants are physiotherapy interns.

Given that only $15 \%$ of the respondents in our study had ever reported the mistreatment, there is a possibility the experience is seriously underreported. Sixty-five percent of the interns attributed their unwillingness to report cases of mistreatment to fear. This is similar to previous findings documented by Iftikhar et al. [4]. Slightly above half of our respondent even believed reporting mistreatment will not accomplish any positive outcome. This is most likely a result of massive mistrust of the system as some thought that the problem would not be treated fairly. This may imply that there is no enabling environment for reporting mistreatment.

The small sample size is one of the limitations of the findings of this study. Likewise, the questionnaire was a closed-ended questionnaire adopted from a foreign country. As such, some specific information to interns in Nigeria may not have been captured.

\section{Conclusion}

Most physiotherapy interns experience mistreatment during the 1-year mandatory clinical internship. Verbal abuse is the most prevalent form of mistreatment, while the least is physical abuse. This study found that mistreatment has adverse effects on the health and work output of physiotherapy interns. Some of the respondents even believed reporting mistreatment would make no difference. This disbelief in the system to check for mistreatment may predispose interns to a perpetual cycle of mistreatment, which would only undermine the physiotherapy training.

\section{Recommendation}

There is a need to promote a supportive environment for interns during their training and develop appropriate strategies that will restrict or prevent mistreatment among this group of professionals.

\section{Supplementary Information}

The online version contains supplementary material available at https://doi. org/10.1186/s43161-021-00033-z.

Additional file 1. This is the instrument used for data collection.
Acknowledgements

We hereby appreciate all interns who participated in the study.

Authors' contributions

DG conceived the study and helped in the data collection, analysis, and drafting of the manuscript. TG, IA, AT and HY help in the data collection and drafting the manuscript. All authors read and approved the final version of the manuscript.

Funding

Study was self-funded.

Availability of data and materials

Is not available online.

\section{Declarations}

Ethics approval and consent to participate

Ethics approval was obtained from Kano state ministry of health. However, here was no research ethics committee (REC) number given.

Written informed consent to participation was sought and obtained from the participant.

Consent for publication

Not applicable

Competing interests

Authors declared no competing interests.

\section{Author details}

${ }^{1}$ Physiotherapy Department, Abubakar Tafawa Balewa University Teaching Hospital, Bauchi, Nigeria. ${ }^{2}$ University of Ibadan, Ibadan, Nigeria. ${ }^{3}$ Aminu Kano Teaching Hospital, Kano, Nigeria.

Received: 10 February 2021 Accepted: 26 May 2021

Published online: 14 July 2021

References

1. Ellis S, Purkiss J, Abdoler E, Opaskar A, Mangrulkar RS, Kolars JC, et al. Variability in student perceptions of mistreatment. Clin Teach. 2018;15:1-5.

2. Cook AF, Arora VM, Rasinski KA, Curlin FA, Yoon JD. The prevalence of medical student mistreatment and its association with burnout. Acad Med. 2014;89(5):749-54.

3. Markman JD, Soeprono TM, Combs HL, Cosgrove EM. Medical student mistreatment: understanding 'public humiliation'. Med Educ Online. 2019; 24(1):1615367. https://doi.org/10.1080/10872981.2019.1615367.

4. Iftikhar R, Tawfiq R, Barabie S. Interns' perceived abuse during their undergraduate training at King Abdul Aziz University. Adv Med Educ Pract. 2014;5:159-66. https://doi.org/10.2147/AMEP.S62890.

5. Coverdale JH, Balon R, Roberts LW. Mistreatment of trainees: verbal abuse and other bullying behaviors. Acad Psychiatry. 2009;33(4):269-73.

6. Tepper BJ. Consequences of Abusive Supervision. Acad Manag J. 2000;43(2): 178-90.

7. Silver HK. Medical students and medical school. JAMA. 1982;247:309-10.

8. Frank E, Carrera JS, Stratton T, Bickel J, Nora LM. Experiences of belittlement and harassment and their correlates among medical students in the United States: longitudinal survey. BMJ. 2006;333(7570):682. https://doi.org/10.1136/ bmj.38924.722037/7C.

9. Rautio A, Sunnari V, Nuutinen M, Laitala M. Mistreatment of university students most common during medical studies. BMC Med Educ. 2005;5:36. https://doi.org/10.1186/1472-6920-5-36.

10. Timm A. It would not be tolerated in any other profession except medicine: survey reporting on undergraduates' exposure to bullying and harassment in their first placement year. BMJ Open. 2014;4(7):e005140.

11. Dyrbye LN, Thomas MR, Shanafelt TD. Medical student distress: causes, consequences, and proposed solutions. Mayo Clin Proc. 2005;80(12):1613-22.

12. Yildirim D. Bullying among nurses and its effects. Int Nurs Rev. 2009:56:504-11.

13. Onigbinde AT. 2007. The impact of internship programme and its effects on the physiotherapy practice in Nigeria. Niger Med Reh. 2007;11(2):86-91.

14. Mukhtar F, Daud S, Manzoor I, Amjad I, Saeed K, Naeem M, et al. Bullying of medical students. J Coll Physicians Surg Pak. 2010;20(12):814-8. 
15. Owoaje ET, Uchendu OC, Ige OK. Experiences of mistreatment among medical students in a university in south west Nigeria. Niger J Clin Pract. 2012;15(2):214-9.

16. Salvador PTCO, Alves KYA, Rodrigues CCFL, Oliveira LV. Online data collection strategies used in qualitative research of the health field: a scoping review. Rev Gaúcha Enferm. 2020;41:e20190297. https://doi.org/10.1 590/19831447.2020.20190297.

17. Medeiros M. Thinking about qualitative research [editorial]. Rev Eletr Enf. 2012;14(2):226-7. https://doi.org/10.5216/ree.v14i2.13628.

18. Mbada CE, Ogunseun IP, Fasuyi FO, Adegbemigun OD, Fatoye CT, Idowu $\mathrm{OA}$, et al. Prevalence and correlates of bullying in physiotherapy education in Nigeria. BMC Med Educ. 2020;20(1):112.

19. Rayner C, Hoel H. A summary review of literature relating to workplace bullying. J Community Appl Soc Psychol. 1997;7(3):181-91.

20. Alzahrani HA. Bullying among medical students in a Saudi medical school. BMC Res Notes. 2012;5:335.

21. Omigbodun OO, Odukogbe AA, Omigbodun AO, Yusuf OB, Bella TT, Olayemi O. 2006. Stressors and psychological symptoms in students of medicine and allied health professions in Nigeria. Soc Psychiatry Psychiatr Epidemiol. 2006;41(5):415-21.

22. Muhammad DG, Ahmad AA, Usman JS. Assessment of level and sources of stress among allied health sciences students of Bayero University Kano: a comparison between clinical and pre-clinical students. Educ Med J. 2019; 11(1):11-9. https://doi.org/10.21315/eimj2019.11.1.2.

23. Sadock B, Ruiz P. Kaplan \& Sadock's synopsis of psychiatry: behavioral sciences. 10th ed. Mumbai: Philadelphia Indian Reprint; 2015.

24. Menezes RG, Subba S, Sathian B, Kharoshah MA, Senthilkumaran S, Pant S, et al. Suicidal ideation among students of a medical college in Western Nepal: a cross-sectional study. Legal Med. 2012;14(4):183-7.

25. Van Niekerk L, Scribante L, Raubenheimer P. Suicidal ideation and attempt among South African medical students. SAMJ. 2012;102(6):372-3.

26. Dyrbye LN, Thomas MR, Massie FS, Power DV, Eacker A, Harper W, et al. Burnout and suicidal ideation among US medical students. Ann Intern Med. 2008;149(5):334-41.

\section{Publisher's Note}

Springer Nature remains neutral with regard to jurisdictional claims in published maps and institutional affiliations.

\section{Submit your manuscript to a SpringerOpen ${ }^{\circ}$ journal and benefit from:}

- Convenient online submission

- Rigorous peer review

- Open access: articles freely available online

High visibility within the field

- Retaining the copyright to your article

Submit your next manuscript at $\boldsymbol{\nabla}$ springeropen.com 